Max-Planck-Institut für demografische Forschung

Max Planck Institute for Demographic Research

Konrad-Zuse-Strasse 1 - D-18057 Rostock - GERMANY

$\mathrm{Tel}+49$ (0) 3812081 - 0; Fax +49 (0) 3812081 - 202;

http://www.demogr.mpg.de

MPIDR WORKING PAPER WP 2009-028

NOVEMBER 2009

\title{
Maternity leave in turbulent times: \\ Effects on labor market transitions and \\ fertility in Russia, 1985-2000
}

Theodore P. Gerber

Brienna Perelli-Harris (perelli@demogr.mpg.de)

This working paper has been approved for release by: Michaela Kreyenfeld (kreyenfeld@demogr.mpg.de), Acting Deputy Head of the Laboratory of Economic and Social Demography.

(C) Copyright is held by the authors.

Working papers of the Max Planck Institute for Demographic Research receive only limited review. Views or opinions expressed in working papers are attributable to the authors and do not necessarily reflect those of the Institute. 


\section{Maternity leave in turbulent times:}

Effects on labor market transitions and fertility in Russia, 1985-2000

Theodore P. Gerber, University of Wisconsin-Madison

Brienna Perelli-Harris, Max Planck Institute for Demographic Research 


\title{
Maternity leave in turbulent times:
}

\section{Effects on labor market transitions and fertility in Russia, 1985-2000}

\begin{abstract}
Maternity leave policies are designed to ease the tension between women's employment and fertility, but whether they actually play such a role remains unclear. We analyze the individuallevel effects of maternity leave on employment outcomes and on second conception rates among Russian first-time mothers from 1985-2000 using retrospective job and fertility histories from the Survey of Stratification and Migration Dynamics in Russia. During this period Russia experienced tremendous economic and political turbulence, which many observers believed would undermine policies like maternity leave and otherwise adversely affect the situation of women. Nevertheless, we find that maternity leave helped women maintain a foothold in the labor market, especially during the more turbulent post-transition period. Also, women who took extended leave in connection with their first birth had elevated rates of second conceptions once they returned to the workforce.
\end{abstract}


Sociologists and demographers have devoted considerable attention to the conflict between women's employment and fertility (Brewster and Rindfuss 2000, Rindfuss et al. 2003). Because the primary responsibility for childcare falls overwhelmingly on women, combining work outside the home and early childrearing is inherently difficult; only under rare conditions can women undertake both simultaneously. In order to participate in the labor force, women must curtail childrearing (and hence childbearing) or find some alternative means of childcare. Maternity leave potentially reduces the conflict between employment and childbearing, at least temporarily. Maternity leave policies have been enacted to maintain women's participation in the labor force after childbirth, promote gender equality by helping women uphold their position in the labor force, and encourage couples to have more children. However, the evidence that parental leave realizes its potential to improve any of these outcomes is mixed (Ruhm 1998, Gauthier 2007), and it tends to take the form of macro-level analyses using aggregate data that cannot control for factors that may jointly influence maternity leave and other outcomes (Neyer and Andersson 2007).

We evaluate the effects of maternity leave on employment outcomes and childbearing behavior in Russia using individual-level data from the Survey on Stratification and Migration Dynamics in Russia (SSMDR), a rich and comprehensive survey that includes questions on the duration of maternity leave in its retrospective employment histories. The variation in uptake and duration of maternity leave following a first birth allows us to analyze the relationship between maternity leave and women's labor market transitions (entry or exit into the labor market and job mobility), as well as second birth rates. Russia is a particularly interesting case for studying maternity leave due to its history of socialist family policies, the rapid institutional transformation associated with the Soviet collapse, the ensuing economic and political turbulence that may have undermined maternity leave, and a cultural tradition of low father involvement in childrearing. We find that maternity leave has helped Russian women with young children maintain a foothold in the labor market, especially during the period of considerable economic and political turbulence that followed the collapse of the Soviet Union (1992-2000). Moreover, women who took 4 to 36 months of maternity leave following their first birth conceived 
second children at significantly higher rates upon returning to the labor force than women who did not do so.

\section{MATERNITY LEAVE AND EMPLOYMENT}

All industrialized countries have some form of maternity leave policy to help mediate the conflict between childbearing and employment (Gornick et al. 1998), yet the impact of these policies on gender equality in the labor force is uncertain. Some studies demonstrate that the availability of maternity leave has a positive effect on female labor force participation. For example, in the U.S., Great Britain, and Japan, maternity leave has a positive effect on job retention after childbirth (Waldfogel, Higuchi, and Abe 1999). The availability and use of maternity leave also encourages women to return to their previous employer and provides a wage premium that offsets the wage penalty of motherhood (Waldfogel 1998). In a cross-national study Gornick et al. (1998) found that countries with more supportive maternal employment policies experienced less reduction in employment among mothers of infants and preschoolers.

On the other hand, maternity leave policies may have a negative effect on women's labor force participation and gender equality. Although women may be guaranteed employment in the same firm when they return from leave, time out of the labor force may result in lower job retention and poorer wages in the long term (Gangl and Ziefle 2009). There may also be an optimal length of maternity leave, where entitlements to short periods of paid leave have little impact on wages, but longer periods reduce wages (Ruhm 1998). Thus, it is unclear whether maternity leave ultimately benefits or harms women's work trajectories.

In Soviet Russia, the state encouraged women to work and sought to keep them in the labor force by expanding daycare accessibility and quality and allowing mothers to work shorter days with more flexible hours. Paid maternity leave, first introduced in 1981, was another important measure designed to help women balance work and childrearing. Women on maternity leave received full pay up to 112 days, partial-pay up to 18 months, and unpaid leave from 18 to 36 months (Zakharov 2008). 
Eligibility for maternity leave payments did not depend on length of employment, but the amount of the monthly benefits did depend on whether the woman was insured through her workplace. The pay varied across regions, with women in Siberia and the Far East receiving slightly more per month, reflecting the higher living costs and general policy of wage paying wage premia in these regions. In 1990 the maternity leave benefit-scheme was reformed: the basic maternity leave payments remained similar, but employed women now received the minimum wage (70 rubles) for 18 months and women who had never worked receive half the minimum wage for 18 months. Unpaid maternity leave was expanded to three years without interruption of social security benefits and a guaranteed return to previous employer.

Despite very high female labor force participation rates in Soviet Russia (Gerber and Mayorova 2006), true equality in the labor market or the home never materialized, as reflected in exclusions of women from certain occupations, gender wage gaps comparable to those in other countries, and high levels of occupational sex segregation (Ogloblin 1999; Brainerd 2000). Women were expected to work outside of the home, but also to do the majority of childrearing and domestic chores, often called the Soviet “double burden” (Brainerd 2000, Marsh 1996). Therefore, despite extensive female labor force participation, conservative gender roles and norms persisted.

The crisis-like conditions of the Russian economy for much of the 1990s may have undermined the role of maternity leave in maintaining women's attachment to the labor force. The collapse of the state socialist economy and the introduction of market reforms at the outset of 1992 disrupted the labor market, yielding sharp declines in real wages, structural dislocations, growing unemployment, and widespread wage arrears (Gerber and Hout 1998; Gerber 2002, 2006). Some have argued that discrimination against women also increased during this period (CEDAW 1999). State authorities no longer explicitly encouraged women to participate in the labor force, and some policy-makers began to call for women to return to the home to perform their "natural” duties (Teplova 2007). Market forces eroded Soviet institutions and policies that suppressed gender discrimination, potentially giving free rein to latent patriarchal attitudes among male employers (Linz 1996; Ogloblin 1999; Khotkina 2001). 
As social institutions and government enforcement agencies faltered and corruption grew, capitalist firms may have been able to ignore mandates to protect gender equality, instead focusing on profits. In sum, whether driven by new competitive pressures or by latent sexism, employers in the post-Soviet context may have targeted new mothers for layoff and refused to let them take maternity leave.

Even if maternity leave remained an option, women may have had less incentive to take it. Rampant inflation throughout the 1990s reduced the value of maternity leave benefits, often rendering the monthly payments trivial in value (Zakharov 2008). Inflation and the uncertain employment situation also placed pressure on household budgets, making it more costly for women to forego the difference between their wages and their maternity benefit.

On the other hand, maternity leave was instituted to protect women's position in the labor force, and it may have continued to play this role despite the turbulent economic upheavals. It seems unlikely that the strong social protections of the Soviet state dissipated that rapidly after the collapse, and in all likelihood Russians still expected the state to provide services such as universal health care, pensions, and a strong safety net. A study in nearby Ukraine showed that many women expect the government to provide support for families and childbearing, especially paid maternity leave (PerelliHarris 2003). Thus, although the value of maternity leave payments may have declined in post-Soviet Russia, we still expect that it provided employment protection and a way to maintain a foothold in the labor market.

\section{MATERNITY LEAVE AND FERTILITY}

Maternity leave provides a period of time to care for an infant when the infant is establishing secure attachments and developing basic physiological and behavioral regulation (Clark et al. 1997). It allows women to avoid, at least temporarily, the role incompatibility that comes with attempting to raise young children and work simultaneously (Rindfuss et al. 2003). Thus, maternity leave can reduce the opportunity costs of having a child, making it easier for women to achieve their desired number of 
children. Accordingly, some governments have implemented parental leave policies with the explicit goal of encouraging women to have more children.

However, research has produced mixed results on whether these policies affect fertility (Gauthier 2007). The most compelling evidence that changes in parental leave policy can raise fertility is Sweden's "speed premium,” which expanded the length of time parents could retain parental leave benefits without returning to work to two years, resulting in an increase in second birth rates (Hoem 1993). Similarly, in 1990 Austrians increased the tempo of third births following the government's extension of the parentalleave period, helping reverse a decades-long decline in third birth rates; however, overall the changes in parental leave had no impact on total fertility (Hoem, Prskawetz, and Neyer 2001). Finally, father's uptake of parental leave in Sweden is related to higher second- and thirdbirth propensities, but this relationship disappears with extended periods of leave (Duvander and Andersson 2006).

Soviet officials clearly hoped maternity leave would address concerns about falling birth rates, as well as labor supply. Indeed, immediately following the implementation of family policies, Russia's total fertility rate (TFR) grew from 1.89 in 1980 to 2.22 in 1987 (Zakharov 2006). This increase in fertility was merely a tempo effect: the spacing between first and second births shortened, but cohort fertility did not increase in the long run (Zakharov 2006). Nonetheless, we expect that on the individual level, once period effects are controlled, maternity leave does lead to an increase in second birth rates, as it temporarily alleviates the conflict between paid work and childrearing.

The potential contribution of maternity leave to fertility is an especially important concern in post-Soviet Russia, where the TFR declined from 1.89 in 1991 to 1.17 in 1999, one of the lowest levels in the world (Zakharov 2008). Most of the decline reflected postponement or elimination of second births; only in the late 1990s did the postponement of first births begin to play a role (Zakharov 2008). Thus, we focus on the effects of maternity leave on second births, the key parity progression for Russia’s fertility decline. Maternity leave may have helped determine who had second births by 
shaping whether women could successfully balance employment and childbearing after their first births: those who were able to do so presumably would be more likely to decide to have an additional child.

\section{DATA AND ANALYTIC STRATEGY}

We analyze the relationships of maternity leave with employment and fertility outcomes from 19852000 using the Survey on Stratification and Migration Dynamics in Russia (SSMDR). The SSMDR was given to a multistage, stratified probability sample of 7176 Russian adults in three waves from September 2001 - January 2002. For complete information about pre-testing, sampling, fieldwork, and quality control see Gerber (2006b). The instrument included special batteries of questions that elicited the respondent's entire fertility, marital, work, and residential histories from December 1984 through the month of the survey. These histories allow us to estimate hazard models relating births and labor market transitions to maternity leave, while incorporating time-varying covariates.

In a preliminary step we estimate logistic regressions to see how individual characteristics and structural variables (context of employment and locality) relate to the log-odds that a woman who is employed at the time of her first birth takes a leave at least four months long. In addition to shedding light on who takes maternity leaves that extend beyond the period during which full pay is guaranteed, these analyses allow us to control for factors that jointly affect taking longer leaves and the subsequent employment and fertility outcomes we analyze. We include the structural variables associated with taking a leave of over 3 months, as well as the estimated propensity of doing so, in sensitivity analyses of models pertaining to employment and fertility.

To test whether maternity leave enhances the workforce attachment and job mobility of women who have children, we estimate discrete time hazard models for four outcomes: entry to a new job (for those currently unemployed, out of the labor force, or on maternity leave), and job loss, voluntary employment exit (quits), and employer change (for those currently working or on maternity leave). For all our analyses, we define maternity leave strictly as maternity leave from a job, because our substantive interest focuses specifically on whether and how maternity leave from paid employment 
helps women combine work and childbearing. We incorporate women into the risk sets for all four outcomes during months when they are on maternity leave from a job, and we estimate the effects of being on leave on the hazard of experiencing each outcome relative to being out of the labor force (for job entry) or to hired employment (for job shift to a new employer, job loss, and voluntary quit). It may seem contradictory to treat women on maternity leave from a job as simultaneously at risk for employment entry (implying they are not currently employed) and for job loss, voluntary employment exit, and employer change (implying they are currently employed). However, as a labor force status maternity leave shares some characteristics with both non-employment (women on leave from a job are not actively working) and employment (they formally hold a job, have an employer, etc.). The observation window for these analyses is 1988-2000. Data limitations make it impossible to identify the number of children under 3 living at home for 1985-1987 and pregnancies that began after December 2000.

We next analyze how maternity leave influences subsequent fertility using discrete-time hazard models of second conception rates for women who remain in the workforce after their first births. The dependent variable is the log-odds of having a second conception in a particular month. Respondents enter the risk set the month following their first birth and are censored at the time of the interview or a conception that ends in a second live birth. Because we are interested in whether maternity leave is associated with higher rates of second conceptions among working women, we censor person-months when respondents are out of the labor force - i.e., when they are not working, unemployed and looking for work, on maternity leave from work. Women who leave the labor force (e.g., to study or keep house full time) re-enter the risk set if and when they re-enter the labor force. We relax these risk set restrictions and try additional restrictions in sensitivity analyses.

We backdate conceptions to 8 months before the birth, which is often when the decision to keep a pregnancy is made. Unfortunately, the survey did not ask about abortions or miscarriages, or about whether respondents were pregnant at the time of the interview. We do not observe any conceptions 
within a nine-month window preceding the interview. The date of interview varies, so for simplicity we truncate our observation window at the end of December 2000 for all respondents.

\section{Independent Variables.}

Main Activity. The main activity histories asked respondents to identify the month and year when they started a "leave due to pregnancy or to look after a child," and also each time they returned from maternity leave to their prior job or to a new job (the latter two alternatives were distinguished, allowing us to identify job changes by women while on maternity leave). They also asked the month and year of any job losses, voluntary quits, employer changes, new jobs, and other changes of workforce status (starting to look for work, entering full-time schooling, leaving the work force due to retirement or disability, etc.) We use this information to identify the respondent's main activity each month during the observation period. We code respondents who are not working and not looking for work as "not in the labor force," while those who have no job but are actively looking for work are “unemployed.” Other options include: working for hire, self-employed, studying in school, serving in the military, retired/disabled, or other activity.

Maternity leave. In the employment models, we specify maternity leave as a dummy variable indicating whether a woman is on maternity leave in a given month. In the fertility models we distinguish the effects of current and prior maternity leave by incorporating separate time-varying variables for each. While a woman is on maternity leave, the reduced income from maternity leave (after 112 days) compared to work might discourage her from having an additional child; alternatively, the ability to retain her job may encourage her to become pregnant again. Once they return to work, women may have higher second birth rates if they had a positive experience during maternity leave, since it allowed them the chance to devote time to early child-rearing free from anxiety about losing their job (and included a modest, albeit reduced income).

In addition, the effects of both current and prior maternity leave on second conception rates might vary by duration. We initially categorize duration of current and prior maternity leaves as follows: $0-3$ months, 4-12 months, $13-18$ months, $19-36$ months, and 37+ months. The first category 
approximately corresponds to the period when women can receive their full salary while on leave; and, because it is so common to take at least some maternity leave, we do not distinguish among from 0 to 3 months. By the end of the fourth month of maternity leave, women receive reduced compensation; thus, we expect the key dividing line in terms of maternity leave duration effects to be between the first and second categories. The third category is based on the natural psychological benchmark of one year. The fourth category (19-36 months) is the period when women are not guaranteed any compensation at all, yet they formally have the right to return to their jobs. The final category captures maternity leave longer than the three years to which women are legally entitled. These cases of extremely long leave may reflect the need to care for disabled children, special arrangements with employers, some other unusual circumstance, or misreporting. Our analyses revealed variation by duration only for the effects of prior maternity leave on second conception rates, with the key distinction between 0-3 months and 436 months. We found no significant variations by duration in our analyses of labor market outcomes so we only report the results of models using a single time-varying dummy variable measure of current maternity leave.

Structural variables. Our models incorporate variables characterizing the woman's job and locality at the time of her first birth. Three measured aspects of the employing firm may be relevant: sector, branch, and size. We expect private employers to discourage employees from taking extended leave, because they face tighter budget constraints and are focused on profit motives that make them less willing to hire and train replacements for employees on leave. Firms in different branches of the economy may have different tendencies regarding compliance with maternity leave based on their average wage levels (which affect the costs of paying leaves), the flexibility of their work processes, the costs of hiring and training replacements, and their degree of competitiveness. We have no prior expectations for specific patterns, so we use dummy variables corresponding to twelve branch categories, which we contrast with "manufacturing." We expect larger firms to be more tolerant of extended maternity leave since they have greater capacity to redistribute their existing workforce to cover for employees on leave. 
We employ two measures of occupational characteristics. The occupation associated with each job held by the respondent was initially coded using the 1988 ISCO classification. We used scales developed in other studies (see Gerber and Mayorova 2006) to code occupations by their percentage of female incumbents and their average logged earnings. Following human capital reasoning about gender differences in occupational choice (e.g. Polachek 1981), we would expect more feminized occupations to be associated with higher rates of extended maternity leave and better-paying occupations to be associated with lower rates of extended maternity leave.

We test for systematic variation by regional characteristics using the logged population size of the respondent's locality at the time she gives birth, a dummy variable for residence in Moscow, and three variables describing the province of residence: average logged wages (adjusted for inflation), the unemployment rate, and the percentage of ethnic Russians according to the 1989 census. We might expect longer maternity leaves to be more common in regions that are performing better economically, as workers in such regions might be less fearful of dismissal in retaliation for taking an extended leave. At the same time, the average wage penalty for taking an extended leave would be higher in higherwage regions, which might create a disincentive for extended leave. Following Gerber and Berman (2009), we treat the percentage of ethnic Russians as a proxy for relatively stronger cultural orientation toward Western norms regarding work and family, because many non-Russians are Muslims. As a Western institution associated with feminist norms, extended maternity leave might be more culturally accepted in regions where Muslims represent a smaller contingent of the population.

Period measures. It is important to control for the sweeping changes in Russian society that occurred throughout the period of observation. In brief, initial signs of economic trouble and political instability emerged in the late 1980s, when Russia’s fertility decline started. Full blown crisis conditions erupted at the end of 1991, when the Soviet Union collapsed, and continued until a period of sustained growth began in 1999. Our models specify period using dummy variables for 1985-1987, 1992-4, 1995-8, and 1999-2000, representing the early pre-transition and early, middle, and later transition periods, which are compared to the late pre-transition baseline of 1988-1991. We test for 
change in the effect of maternity leave on labor market transitions using an interaction between maternity leave and a dummy variable for post-1991. We found no significant interactions between maternity leave and period in the fertility model, so we do not include them in the results we report.

Other controls. The employment models include controls for age, education, marital status, current pregnancy, number of children under 3, number of children over 3, and period effects. The optimal specifications of these variables are taken from (REFERENCE OMITTED), where we also discuss these effects in considerable depth. Here we focus exclusively on the impact of maternity leave on the outcomes in question. Where appropriate, we also include structural variables (job and locality characteristics) that influence who takes extended leave, in order to reduce the potential for omitted variable bias. The fertility models also control for standard variables that influence fertility. We specify respondent's current education using dummy variables for university, specialized secondary, and less than secondary (contrasted with secondary education, including vocational secondary). Preliminary analysis showed that the optimal specification for age includes age and age-squared (both centered at the analysis sample minimum of age 15), while the optimal specification for the timing of first birth includes a third-order polynomial expression of months since first birth (months, months squared, and months cubed). We also control for relationship status, city size, and Moscow residence.

\section{RESULTS}

\section{Descriptive statistics}

Table 1 shows the duration of maternity leaves by birth parity for women aged 15 to 44 . The modal duration (using five categories) is the shortest period of maternity leave ( 0 to 3 months), but female SSMDR respondents took longer leaves following 60\% of births reported from January 1985June 1999. Given the difficult economic conditions during this period, the $40 \%$ of women who did not take extended maternity leave may have needed to return to work to supplement their household incomes. Also, alternative forms of childcare that facilitated women's return to work were available, such as subsidized daycare and help from grandmothers. About $43 \%$ took leaves beyond the period 
during which they received at least partial compensation: $28 \%$ took 19 to 36 months, and $15 \%$ took more than three years. Thus, extended periods of leave (over 3 months) are quite common in Russia. Also, they are somewhat more typical following first births than second or third births.

[TABLE 1]

For descriptive statistics on the control variables in our models, see Appendix Table A1. The trends in these variables over time reflect known trends in Russia over the period in question, such as increasing unemployment and private sector employment, stable rates of female educational attainment, and declining marriage and fertility.

\section{Correlates of Extended Maternity Leave after First Birth}

Our first logistic regression model for the log-odds of taking an extended leave (four months or more) in connection with a first birth includes only individual demographic characteristics and period (Table 2). Consistent with bivariate patterns (not shown), the use of extended maternity leave does not vary systematically by age, education, and marital status. This remains the case when we control for structural variables. Model 2 includes a pared down set of structural variables: to save space, we include only those branch dummy variables that approach significance and we omit the non-significant effect of firm size. For our preferred model we remove the individual demographic variables and the remaining non-significant structural variables. The effect of "public safety and administration” is nearly significant ( $\mathrm{p}=.106$ ), so it stays in the preferred model (though removing it does not affect any other inferences).

[Table 2]

Structural variables associated with a first-time mother's job and place of residence influence the probability that she will take extended leave. Women working for private sector firms are significantly less likely to do so. Private employers are probably more reluctant to hire and train temporary replacements and women may be worried about losing their jobs. State sector employers may feel more compelled to comply with laws governing maternity leave and, on average, face fewer competitive pressures to reduce labor costs. The lower probability that private sector employees take 
extended maternity leave could also reflect the higher average wages in the private sector and the greater wage losses that private employees incur when they take leave beyond the full-pay period. This interpretation is a twist on theories attributing lower childbearing rates of women in higher paying occupations to higher opportunity costs (Becker 1991). In Russia, opportunity costs may not reduce first births, which are nearly universal, but instead impact time spent on maternity leave. We found no significant effect of firm size, but we did identify three branches where, net of the other effects, extended maternity leaves are less common: health and social services, public safety and administration, and finance and insurance. The latter branch is known for its especially high wage rates, again raising the opportunity costs of taking extended maternity leave. We have no explanation why women who work in health and public services would be less likely to take extended leaves.

Women in more highly feminized occupations are significantly more likely to take extended maternity leaves in connection with their first birth. This is consistent with straightforward human capital reasoning: women more oriented toward childrearing than career achievement may be drawn disproportionately to occupations that offer flexible maternity leave arrangements. Thus, the percent female in a respondent's occupation may be viewed as a proxy for an unobservable orientation toward career vs. child-rearing rather than a causal factor encouraging maternity leave. In contrast, better paying occupations are also associated with elevated odds of taking extended leave, which contradicts human capital logic. This effect obtains whether or not we control for private sector employment. Perhaps women in higher-paying occupations are better off economically, both due to their relatively high-paying jobs and to assortative mating, and can more easily afford sacrificing some of their wages while on extended leave. Or, the maternity leave rights of salaried employees could be better protected than those of wage employees.

Net of the other variables in the model, extended maternity leave is significantly more common in Moscow than in other locations. We speculate that the enforcement of maternity leave compensation policies might be more reliable in Moscow. Also, they are more common in regions with higher rates of unemployment, which is contrary to our expectations. Perhaps women see extended leave as a 
protection against losing their job in regions where job loss is more widespread, or women may have been strongly encouraged to take maternity by employers facing budget constraints, similar to a forced furlough. We do not find any significant effect of regional average wage, but we do find the expected positive effect of the percentage of ethnic Russians in the region. Finally, net of the structural controls, extended leaves spiked during the period 1999-2001, when Russia’s economy began growing again.

The pronounced relationships between the structural variables and the odds of taking extended maternity leave in Russia are especially striking given the lack of variation by individual demographic characteristics. Although to some extent these structural variables may influence whether women take extended maternity leave via the attitudes of employers and the relative costs and benefits extended leave, the relationships are probably at least partly endogenous. Although maternity leave laws apply, in principle, to all work settings, employers most likely vary in their degree of compliance with the law, and work situations vary in terms of the longer-term costs of taking extended leave to women's careers. Women who want to take extended maternity after their first birth probably choose occupations and employers based, at least in part, on whether they are promising in terms of offering full benefits and exacting minimal costs for doing so. For this reason, by incorporating in our models for employment outcomes and second conceptions the structural variables associated with extended leave or a respondent's propensity to do so, which we estimate from Model 2 in Table 2, we control for at least some unobserved factors that can bias estimates of the effects of extended leave on these outcomes. Effects of maternity leave on labor market transitions

As mentioned above, our models for labor market transitions stem from our work on the relationship between family structure and employment transitions (REFERENCE OMITTED). In the models shown here, we incorporate the effects of maternity leave into the previously specified models. To illustrate the specifications of these models, we show three detailed model specifications from our analysis of job loss (Table 3). Models 1 and 2 control only for individual demographics and household composition. These models show that maternity leave is associated with a lower hazard of job loss (relative to the baseline category of active employment), but only in the post-Soviet period: removing 
the "main effect" does not lead to a significant loss of model fit and it results in a statistically significant effect of the maternity leave-by-post-1991 interaction. Model 3 adds controls for the structural variables that affect the odds of taking an extended leave, in order to correct for potential bias in the estimate of the effect of maternity leave on the outcome. The post-1991 maternity leave effect barely changes magnitude and remains statistically significant. Note, as well, that several controls have the effects we would expect: university education lowers rates of job loss (Gerber 2002), while private sector employees and residents in regions with higher unemployment rates have elevated hazards of being laid off. In an additional modeling step (not shown), we enter interactions between the other household structure and employment variables and the post-1991 dummy, in order to make sure that the maternity leave-by-post-1991 effect is not picking up a complex pattern of change in the baseline categories.

[Table 3]

Table 4 shows significant effects of maternity leave on all four labor market outcomes. In this table, we report separate results from models estimated on the entire sample of 15-44 year old women and models estimated on a restricted sample of women with children under 3 in the household. The former offer more statistical power, but the latter are perhaps easier to interpret, because they pertain only to women who are exposed to the risk of maternity leave (since they have children under 3). For each outcome, maternity leave has a significant and positive effect on women's labor force attachment. The same pattern of results holds whether we analyze the sample of person-months for all women aged 15-44 or women with children under 3. But in some cases maternity leave only has an effect during the post-Soviet era.

[Table 4]

Compared to women who are not in the labor force - i.e., those who have no job and who are not looking for work - women on maternity leave with otherwise identical characteristics were substantially more likely to enter work after the Soviet collapse. The effect is especially strong for those with a child under three at home: the hazard ratio is 2.55. Apparently, maternity leave had little 
impact on women's access to employment during the Soviet era, when jobs were generally plentiful, but it plays an important role in securing women's access to employment during the post-Soviet era, when jobs became scarcer.

A similar conclusion follows from our results with respect to job loss. As noted above, during the Soviet era, when layoffs were rare, women on maternity leave were no more or less likely to lose their jobs than women who were actively working. But after the Soviet collapse, when layoffs became far more common due to the sharp economic contraction accompanying market reforms, maternity leave dramatically reduced exposure to layoffs: while on maternity leave, women's hazard of layoff was only about $1 / 3$ that of otherwise similar women who were actively working. Thus, during the postSoviet era maternity leave not only gave women enhanced access to employment (relative to simply being out of the labor force), it also protected women from being laid off. Neither effect obtained during the late Soviet period. Despite concerns that maternity leave policies were weakly enforced in the post-Soviet era, it appears that precisely during this period the policies protected Russian mothers' access to employment.

Our models for the other two outcomes also revealed significant effects of maternity leave, but in these cases the effects obtained during both the Soviet and post-Soviet periods: the interaction term between maternity leave and the post-Soviet dummy variable was not significant, but the main effect of maternity leave was significant in both models. Women on maternity leave were about $1 / 3$ less likely to quit their jobs than women who were actively working and had the same characteristics on all the control variables. This suggests that maternity leave has helped Russian women maintain their place in the workforce.

Finally, women on maternity leave had rates of job mobility (employer change) about twice as high as women currently working with similar characteristics. This finding is somewhat counterintuitive, because it seems like women who are on maternity leave might not be attractive hires for prospective employers. However, the effect obtains both for the whole sample and among women with children under 3, which implies that we cannot attribute a tendency for women on maternity leave 
to change their criteria for more "child friendly" jobs as a result of having young children. It may be that women on maternity leave experience more pressure to change jobs from employers who want them to leave, or that they are replaced at their original firms, offered less attractive jobs when they return, and decide to seek a new job instead. It seems less likely, though not implausible, that some women on maternity leave have more time to search for new job opportunities compared to women with young children who are actively working. If a woman is unhappy with the conditions of her current job, maternity leave might afford her the chance to seek a better situation elsewhere.

Our evidence that maternity leave is beneficial to Russian women's attachment to and success in the labor force is clear and consistent. Moreover, in stark contrast to the pessimistic scenarios raised by concerned observers who feared that maternity leave policies had become ineffective after the Soviet collapse, our analyses show that in fact the labor market benefits of maternity leave increased during the post-Soviet era.

Finally, we estimated a series of models designed to test whether women who previously took extended maternity leave are more likely to suffer adverse employment outcomes (in particular, job loss or voluntary quit) after returning to work. Employers may routinely punish women for extended leaves after the fact, when they have greater legal leeway to do so. We did not find any statistically significant effects of prior extended leave on the rates of job loss or voluntary quits of women with one child who had returned to work. However, the point estimates were positive, implying an adverse impact of prior maternity leave, and they approached statistical significance. Therefore, the safest conclusion is that maternity leave may be a mixed blessing with respect to employment outcomes, but our data only permit us to conclude that current maternity leave has positive effects on women's employment outcomes.

Effects of maternity leave on subsequent fertility

Our analysis of the hazard of a second conception for women in the workforce shows that current maternity leave has no effect at all, but prior maternity leaves of 4 to 36 months are linked with elevated second conception rates (Table 5). Model 1 includes only standard control variables that affect 
second conceptions, including age, age-squared, education, place of residence, time since first birth (specified as a third-order polynomial transformation of months since first birth, the optimal specification based on preliminary analysis), marital status, and period. Next we add dummy variables for current maternity leave and the full set of prior maternity leave categories (model 2). Current maternity leave has no association with second conception rates (the same conclusion applies when we enter dummies corresponding to different durations of current maternity leave.) But prior maternity leaves of durations 4-12, 13-18, and 19-36 months are associated with higher rates of second conception than prior leaves of 0-3 months. Although only the 19-36 month period differs significantly from the 0-3 months in model 2, the point estimates for 4-12 and 13-18 are similar and do not differ significantly from the estimate for 19-36 months. Therefore, we constrain the coefficients on the three durations to be the same and omit the effect of prior leave exceeding 36 months (model 3). Model 3 suggests that working women who took 4 to 36 months of maternity leave following their first birth have $44 \%$ higher odds of a second conception than working women who took either 0 to 3 or 37+ months of leave.

[Table 5]

The effects of control variables all conform to expectations. Unemployed women have lower odds of a second conception than working women (although the effect is not significant). Women with university education have lower odds of a second conception than women with a general secondary degree or less. Married and cohabiting women have higher rates of second conceptions than single mothers. The effect of age is curvilinear, and the third order specification of time since first birth fits the data. The odds of a second conception initially increase, but at a markedly slower rate than observed in countries where the modal spacing between first and second births is approximately two years. Second conception rates are lower in big cities, but net of city size they are higher in Moscow. The period effects capture the dramatic decline in second birth rates over the period under study. Sensitivity Analysis 
We estimated a variety of alternative models to see how robust our positive results for the effect of prior maternity leave on second conceptions are to model specification and other assumptions (Table 6). First, we specified the effect as "extended maternity leave” by our definition (any leave exceeding 3 months) and also a single dummy variable for 19-36 months. Although the "extended maternity leave" effect is only significant at the $\mathrm{p}<.05$ level using a one-tailed test, it nonetheless reassures us that our earlier analysis of factors related to extended maternity leave has relevance for second conception rates. Also, we have no grounds to prefer the 19-36 specification over the 4-36 month specification, which is significant at the .05 level using a two-tailed test.

\section{[Table 6]}

Next we tried alternative conceptions of the risk set. We included person-months where the respondent is not in the labor force (at home or in school) to check whether omitting women when they are not in the labor force is responsible for our key finding. Because no self-employed women took extended leave with their first birth or reported a second conception, we tried omitting person-months when respondents were self-employed. To ensure that our results were not driven by the behavior of unemployed women and women currently on maternity leave, we tried omitting these two types of spells, alone and in combination with self-employment spells. Finally, because prior maternity leave of at least 4 months can only obtain for women at least 3 months after their first birth (during which time conception rates are lower), we tried omitting spells within 5 months of first birth. In every case, we obtain a similar point estimate for the effect of prior maternity leave as that from our preferred model, and the results are all statistically significant at the .05 level using two-tailed tests.

Our next analyses attempt to control for unobserved heterogeneity. To the extent that the structural factors associated with the probability of taking extended leave with first birth represent choices women made based on their orientations toward child-rearing vs. career, incorporating these factors in our fertility model should at least mitigate potential bias due to unobserved heterogeneity. We first included the structural variables from model 3 in Table 2. In a second approach, we estimated individual-level propensities for taking extended maternity leave using the more complete model 2 in 
Table 2, and entered these estimated propensities as covariates in our second conception model. This latter approach controls, as best we can with our data, for the latent orientation toward taking maternity leave. In neither case does our inference about the effect of prior maternity leave on second conceptions change. We certainly do not maintain that these controls fully parameterize unobserved factors that might jointly affect the decision to take a leave of 4 to 36 months and also the decision to have a second child. But it is reassuring that our attempt to correct for this source of bias led to virtually identical results. Finally, even if the covariates of interest are uncorrelated with unobserved factors that influence the outcome at the outset of the observation period, they may become correlated over time due to differential censoring of respondents, producing dynamic selection bias. To check for this type of bias, we specified the preferred model in a continuous time framework with a person-level random effect (shared frailty), again finding that our result holds up. In sum, although there may still be unobserved characteristics that jointly influence maternity leave and second birth rates, our sensitivity analyses increase our confidence that extended maternity leave increases the rate of second conceptions among working women.

\section{DISCUSSION}

In Russia maternity leave helps alleviate the conflict between work and childbearing: it both promotes women's attachment to the labor force and it increases fertility. Our results show that women are one-third less likely to quit employment when they are on maternity leave, suggesting that maternity leave acts as a placeholder for women in the labor force during the early years of childrearing. As women reenter the labor force, they are nearly twice as likely to change jobs as women who are currently working. This finding indicates that even though women may be compelled to find new jobs when they reenter employment, employers were still willing to hire women that have been on maternity leave rather than assuming their skills deteriorated as they were caring for young children.

Maternity leave provided an even more important role in protecting Russian mothers' access to employment during the post-Soviet economic crisis. Although jobs were in short supply, women on maternity leave had a hazard of reentering employment twice as high as those who were unemployed or 
not in the labor force. During the Soviet period, when jobs were plentiful, maternity leave had an ambiguous effect on entering employment (no effect at all when restricting the analysis to women with children under 3 in their home), suggesting that the policy was only truly effective in the post-Soviet period. The policy also appears to have protected women from being laid off; women who were on maternity leave had a hazard of layoff only about $1 / 3$ of otherwise similar women who were actively working. This finding counters claims that the introduction of capitalism allowed for increased discrimination against mothers or that firms were able to ignore maternity leave regulations and lay off workers. Instead, our results provide evidence that maternity leave policies continued to help women negotiate the early months of childrearing and maintain an attachment to the labor market.

Women who took 4-36 months of maternity leave and then returned to work had significantly higher odds of a second conception in any given month than working women who had previously taken 0-3 or 37+ months. This result holds up in an extensive set of sensitivity analyses. The impact of prior extended maternity leave on second birth rates is particularly important given the steep decline in fertility throughout the study period--the birth interval between first and second births has traditionally been long in Russia, but during the post-Soviet period the interval widened even further (Zakharov 2008). Apparently prior maternity leave shortened the interval, although there was no difference in the effect on second birth rates before and after the collapse of the Soviet Union. The fact that the effect of maternity leave was only significant after a woman returned to work suggests that mother's employment helped families afford a second child. This finding is consistent with economic theories of fertility which argue that parents consider the affordability of children in their childbearing decisionmaking (Kohler, Billari, and Ortega 2002).

This study leaves some questions unanswered. We are unable to measure the impact of changes in maternity leave policies or access to benefits. Because our retrospective job histories only ascertain whether women actually took maternity leave, we do not know whether those who did not were denied that option, nor do we know whether women actually received the benefits they were 
entitled to by law. In the absence of data on husband's or partner's characteristics, we cannot test whether they influence either the probability of taking extended leave or the effects of maternity leave.

Also, we cannot rule out the possibility that the "effects" of taking maternity leave on both employment and on fertility are artifacts of unobserved heterogeneity: in particular, women who are more oriented to childrearing than career may be more likely to take a leave of 4 to 36 months, but they would have higher second conception rates regardless of the actual leave-taking patterns. But our controls for the propensity to take extended leave did not alter our results. Thus, the most plausible explanation for the effect of prior maternity leave is the straightforward one: having a positive experience with maternity leave the first time around (and thus extending it beyond the minimal 3 month period) enhances working women's confidence that they can effectively combine work and family obligations the second time around.

Limitations notwithstanding, our study breaks new ground by directly examining individuallevel associations of maternity leave with employment transitions and fertility. Previous research has posited that women limit their fertility to accommodate their labor force activity or adjust their labor force behavior to their fertility, depending on institutional support (Brewster and Rindfuss 2000). Our findings strongly suggest that maternity leave provides a mechanism for balancing work and family, an undertaking which has become increasingly more difficult in industrialized countries. These effects are particularly noteworthy in light of the rapidly changing economic, political, and social environment in Russia during the post-Soviet period. Even though the level of maternity leave benefits varied during this turbulent period, the period of work-free time still effectively promoted attachment to the labor force and higher second birth rates. Given that uncertainties in the labor market and very low fertility continue to plague Russia, this research shows that it is important for maternity leave policies to be maintained. 


\section{REFERENCES:}

Becker, G. 1991. A Treatise on the Family. Cambridge, Mass.: Harvard University Press.

Brainerd, E. 2000. "Women in transition: changes in gender wage differentials in Eastern Europe and the former Soviet Union.” Industrial and Labor Relations Review. 54: 138-62.

Brewster, K.L. and R.R. Rindfuss. 2000. "Fertility and women's employment in industrialized nations." Annual Review of Sociology 26:271-296.

Clark, R., J.S. Hyde, M.J. Essex, and M.H. Klein. 1997. Length of maternity leave and quality of mother-infant interactions. Child Development, 68(2): 364-383

CEDAW [Committee on the Elimination of Discrimination Against Women]. 1999. "Fifth periodic reports of States parties: Russia.” United Nations.

Duvander, A-Z. and G. Andersson. 2006. "Gender equality and fertility in Sweden: a study on the impact of the father's uptake of parental leave on continued childbearing." Marriage \& Family Review 39(1/2):121-142.

Gangl, M. and A. Ziefle. 2009. "Motherhood, labor force behavior, and women's careers: an empirical assessment of the wage penalty for motherhood in Britain, Germany and the United States." Demography 46(2): 341-69.

Gauthier, A.H. 2007. "The impact of family policies on fertility in industrialized countries: a review of the literature." Population Research Policy Review 26:323-346.

Gerber, T.P. 2002. "Structural change and post-socialist stratification: labor market transitions in contemporary Russia." American Sociological Review 67(October):629-659.

2006. "Getting paid: wage arrears and stratification in Russia." American Journal of Sociology 111(6):1816-1870.

2006b. Survey of Stratification and Migration Dynamics in Russia, 1985-2001. [Computer file]. ICPSR04206-v1. Moscow, Russia: Vserossiiskii Tsentr Izucheniia Obshchestvennogo Mneniia (VTsIOM) [producer], 2002. Ann Arbor, MI: Inter-university Consortium for Political and Social Research [distributor], July 2006. Available at: http://www.icpsr.umich.edu/cocoon/ICPSR/STUDY/04206.xml.

Gerber, T.P. and M. Hout. 1998. "More shock than therapy: market transition, employment, and income in Russia, 1991-1995." The American Journal of Sociology 104(1):1-50.

Gerber, T.P. and D. Berman. 2009. "Entry to marriage and cohabitation in Russia, 1985-2000: trends, correlates, and implications for the second demographic transition." European Journal of Population. In press.

Gerber, T.P. and O. Mayorova. 2006. "Dynamic gender differences in a post-Socialist labor market: Russia, 1991-1997." Social Forces 84(4):2047-2075.

Gornick, J.C., M.K. Meyers, and K.E. Ross. 1998. "Public policies and the employment of mothers: a cross-national study." Social Science Quarterly 79(1):35-54. 
Hoem, J. 1993. "Public policy as the fuel of fertility: effects of a policy reform on the pace of childbearing in Sweden in the 1980s." Acta Sociologica 36:19-31.

Hoem, J., A. Prskawetz, and G. Neyer. 2001. "Autonomy or conservative adjustment? The effect of public policies and educational attainment on third births in Austria, 1975-96." Population Studies 55(3):249-261.

Kohler, H-P., F.C. Billari, and J.A. Ortega. 2002. "The emergence of lowest-low fertility in Europe during the 1990s." Population and Development Review 28:641-680.

Khotkina, Z. 2001. "Female unemployment and informal employment in Russia." Problems of Economic Transition. 43(9): 20-33.

Linz, S.J. 1996. “Gender differences in the Russian labor market.” Journal of Economic Issues. 30: 161-85.

Marsh, R. 1996. “Anastasiia Posadskaia, the Dubna Forum and the independent women's movement in Russia.” Women in Russia and Ukraine. Cambridge University Press: Cambridge.

Neyer, G. and G. Andersson. 2007. "Consequences of family policies on childbearing behavior: Effects or artifacts?" MPIDR Working paper. Rostock, Germany.

Perelli-Harris, B. 2006. "The influence of informal work and subjective well-being on childbearing in post-Soviet Russia." Population and Development Review 32(4):729-753.

Polachek, S.W. 1981. "Occupational self-selection: A human capital approach to sex differences in occupational structure." The Review of Economics and Statistics 63(1): 60-69.

Rindfuss, R.R., K.B. Guzzo, and S.P. Morgan. 2003. "The changing institutional context of low fertility." Population Research and Policy Review 22:411-438.

Ruhm, C. 1998. "The economic consequences of parental leave mandates: lessons from Europe." The Quarterly Journal of Economics 113(1):285-317.

Teplova, T. 2007. "Welfare state transformation, childcare, and women’s work in Russia.” Social Politics: International Studies in Gender, State \& Society 14(3):284-322.

Waldfogel, J. 1998. "The family gap for young women in the United States and Britain: can maternity leave make a difference?" Journal of Labor Economics 16(3):505-545.

Waldfogel, J., Y. Higuchi, and M. Abe. 1999. "Family leave policies and women's retention after childbirth: evidence from the United States, Britain, and Japan. " Journal of Population Economics 12:523-545.

Zakharov, S. 2008. "Russian Federation: from the first to second demographic transition." Demographic Research 19(24):907-972.

2006. "Demograficheskii analiz effekta mer semeynoi politiki v Rossii v 1980-kh g.” (Demographic analysis of the effects of family policy in Russia in the 1980s.) "Sotsialnaya politika: ekspertiza, rekomendatsii, obzori (SPERO) 5:33-69. 
TABLE 1. Maternity leave duration by birth parity, SSMDR births in Russia, January 1985July 1999

$\begin{array}{rrccccr}\text { Duration (months): } & 0 \text { to } 3 & 4 \text { to } 12 & 13 \text { to } 18 & 19 \text { to } 36 & 37+ & \text { Row N } \\ \text { After first birth } & 37 \% & 6 \% & 11 \% & 31 \% & 15 \% & 665 \\ \text { Second births } & 45 \% & 6 \% & 9 \% & 26 \% & 14 \% & 412 \\ \text { Third births } & 44 \% & 5 \% & 16 \% & 18 \% & 17 \% & 94 \\ \text { Fourth or higher } & 21 \% & 11 \% & 21 \% & 16 \% & 32 \% & 19\end{array}$

$\begin{array}{lllll}\text { Overall } & 40 \% & 6 \% & 11 \% & 28 \%\end{array}$ 
TABLE 2. Logistic Regressions for Extended Maternity Leave with First Birth

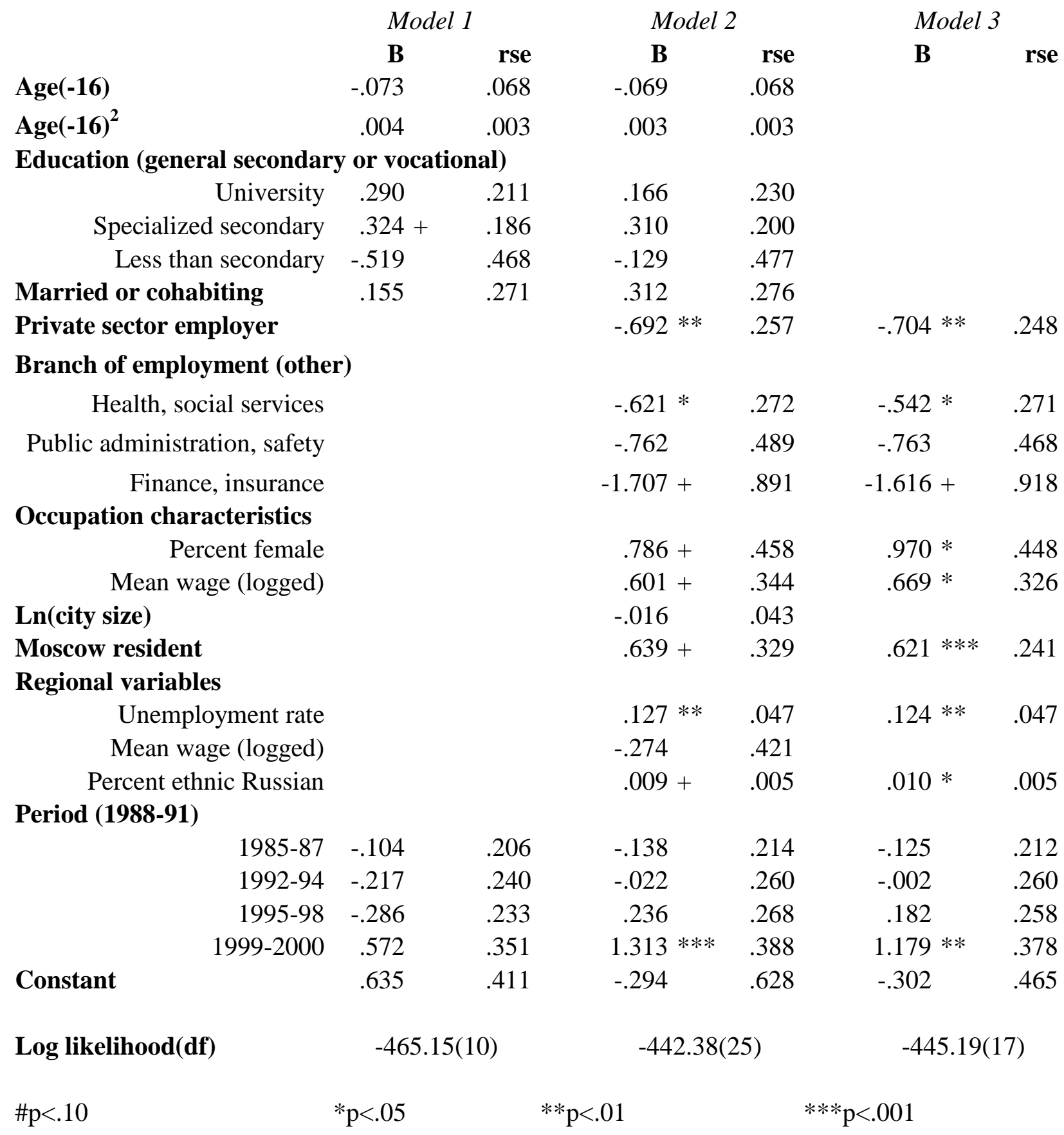

Note: Sample consists of 722 first births reported by SSMDR female respondents ages 16-44 from January 1985-April 2001. Models 2 and 3 include dummy variables denoting missing value substitutions on occupation, place of residence, branch, and sector of employment, but these nuisance parameters are not shown. 
TABLE 3. Discrete Time Event History Models: Job Loss

\begin{tabular}{|c|c|c|c|c|c|c|}
\hline & \multicolumn{2}{|c|}{ Model 1} & \multicolumn{2}{|c|}{ Model 2} & \multicolumn{2}{|c|}{ Model 3} \\
\hline & B & se & B & se & B & se \\
\hline On maternity leave & -.044 & .562 & & & & \\
\hline Maternity leave*post-1991 & -.932 & .673 & $-.973 *$ & .465 & $-.964 *$ & .466 \\
\hline $\operatorname{Age}(-15)$ & -.007 & .009 & -.007 & .009 & -.007 & .009 \\
\hline \multicolumn{7}{|c|}{ Education (general secondary or vocational) } \\
\hline University & $-.340 *$ & .147 & $-.340 *$ & .147 & $-.418 *$ & .157 \\
\hline Specialized secondary & -.189 & .138 & -.189 & .138 & -.170 & .138 \\
\hline Less than secondary & .387 & .240 & .388 & .240 & .385 & .244 \\
\hline \multicolumn{7}{|l|}{ Partner status (no partner) } \\
\hline Married & -.010 & .138 & -.010 & .137 & .007 & .135 \\
\hline Cohabiting & .121 & .263 & .121 & .262 & .106 & .263 \\
\hline One child under three & -.339 & .235 & -.345 & .221 & -.326 & .222 \\
\hline On child three or older & -.028 & .157 & -.028 & .157 & -.032 & .158 \\
\hline Two or more three plus & .133 & .142 & .133 & .142 & .135 & .142 \\
\hline Pregnant & -.416 & .458 & -.418 & .462 & -.412 & .461 \\
\hline \multicolumn{7}{|l|}{ Occupational variables } \\
\hline Percent female & & & & & -.207 & .270 \\
\hline Mean wage (logged) & & & & & .079 & .219 \\
\hline \multicolumn{7}{|l|}{ Branch of employment (other) } \\
\hline Health, social services & & & & & $-.877 * *$ & .283 \\
\hline Public administration, safety & & & & & .069 & .264 \\
\hline Finance, insurance & & & & & .404 & .313 \\
\hline Private sector employer & & & & & $.301 *$ & .132 \\
\hline Moscow resident & & & & & $.457 * *$ & .172 \\
\hline \multicolumn{7}{|l|}{ Regional variables } \\
\hline Unemployment rate & & & & & $.053 *$ & .024 \\
\hline Percent ethnic Russian & & & & & -.001 & .004 \\
\hline \multicolumn{7}{|l|}{ Period (1988-91) } \\
\hline 1992-94 & $.995 * * *$ & .177 & $.998 * * *$ & .173 & $.998 * * *$ & .176 \\
\hline 1995-98 & $1.150 * * *$ & .172 & $1.154 * * *$ & .169 & $1.236 * * *$ & .179 \\
\hline 1999-2000 & $1.255 * * *$ & .192 & $1.258 * * *$ & .189 & $1.341 * * *$ & .201 \\
\hline Constant & $-7.080 * * *$ & .215 & $-7.083 * * *$ & .214 & $-6.987 * *$ & .376 \\
\hline Log likelihood(df) & \multicolumn{2}{|c|}{$-2559.72(15)$} & \multicolumn{2}{|c|}{$-2559.72(14)$} & \multicolumn{2}{|c|}{$-2538.10(27)$} \\
\hline$\# \mathrm{p}<.10$ & $* \mathrm{p}<.05$ & & 01 & & $<.001$ & \\
\hline
\end{tabular}

Note: Risk set includes person-months when SSMDR female respondents ages 15-44 are working for hire or on maternity leave from hired employment. Model 3 includes dummy variables for missing value substitutions on occupation, place of residence, branch, and sector of employment 
Table 4. Associations of maternity leave from work with labor market transitions

\begin{tabular}{|c|c|c|c|c|}
\hline Event & Job entry & Job loss (layoff) & Voluntary quit & $\begin{array}{c}\text { Job mobility } \\
\text { (employer } \\
\text { change) } \\
\end{array}$ \\
\hline Risk set & $\begin{array}{l}\text { Unemployed, not } \\
\text { in labor force, on } \\
\text { maternity leave }\end{array}$ & $\begin{array}{c}\text { Employed, on } \\
\text { maternity leave }\end{array}$ & $\begin{array}{l}\text { Employed, self- } \\
\text { employed, on } \\
\text { maternity leave }\end{array}$ & $\begin{array}{l}\text { Employed, self- } \\
\text { employed, on } \\
\text { maternity leave }\end{array}$ \\
\hline Contrast group & Not in labor force & Employed & Employed & Employed \\
\hline \multicolumn{5}{|c|}{ Maternity leave effect, all women 15-44 } \\
\hline 1988-1991 & 1.00 & 1.00 & 0.67 & 2.57 \\
\hline $1992-2000$ & 1.75 & 0.38 & 0.67 & 2.57 \\
\hline $\mathrm{N}$ respondents & 1416 & 2493 & 2505 & 2505 \\
\hline $\mathbf{N}$ events & 1482 & 347 & 783 & 938 \\
\hline Months at risk & 54310 & 236252 & 239853 & 239853 \\
\hline \multicolumn{5}{|c|}{ Maternity leave effect, women 15-44 with child(ren) under 3} \\
\hline 1988-1991 & 1.00 & 1.00 & 0.59 & 1.96 \\
\hline $1992-2000$ & 2.55 & 0.30 & 0.59 & 1.96 \\
\hline $\mathrm{N}$ respondents & 814 & 1074 & 1083 & 1083 \\
\hline $\mathbf{N}$ events & 611 & 28 & 118 & 188 \\
\hline Months at risk & 22499 & 35425 & 35712 & 35712 \\
\hline
\end{tabular}

Note: Effects are reported as expected hazard ratios contrasting women on maternity leave to those in the baseline category. All those that depart from unity are significant at $\mathrm{p}<.05$. They are estimated using piecewise constant models controlling for age, education, marital status, pregnancy, number of children under 3 , number of children over 3 , and period. Reduced form models and additional controls for change over time in the effects of family-related variables yielded nearly identical estimates. 
TABLE 5. Models for Second Conception Leading to Birth, Russian Women 16-44, 1985-2000 (53479 person-months from 720 female SMDR respondents working at time of first birth.) Model 1 Model 2 Model 3

B rse

Duration of prior maternity leave (0 to 3 months)

$$
\begin{aligned}
& \text { 4-12 months } \\
& \text { 13-18 months } \\
& \text { 19-36 months } \\
& \text { 37+ months }
\end{aligned}
$$

Current employment status (working)

$$
\begin{aligned}
& \text { Maternity leave } \\
& \text { Unemployed } \quad-.373
\end{aligned}
$$

B

rse

B

rse

\begin{tabular}{|c|c|c|c|c|c|c|}
\hline University & $-.416 *$ & .194 & $-.451 *$ & .201 & $-.459 *$ & .197 \\
\hline Specialized secondary & -.153 & .151 & -.169 & .155 & -.173 & .154 \\
\hline Less than secondary & .417 & .636 & .491 & .619 & .502 & .618 \\
\hline Ln(city size) & $-.115 * *$ & .037 & $-.114 * *$ & .037 & $-.111 * *$ & .038 \\
\hline Moscow resident & $.614 *$ & .256 & $.588 *$ & .259 & $.581 *$ & .258 \\
\hline Months since birth & $.042 * * *$ & .013 & $.032 *$ & .015 & $.033 *$ & .015 \\
\hline Months since birth ${ }^{2} / 100$ & $-.001 * *$ & .000 & $-.049 *$ & .023 & $-.050 *$ & .023 \\
\hline $\begin{array}{l}\text { Months since birth }{ }^{3} / 1000 \\
\text { Period (1988-91) }\end{array}$ & $.002 * *$ & .001 & $.002 *$ & .001 & $.002 *$ & .001 \\
\hline $1985-87$ & $.443+$ & .233 & $.441+$ & .234 & $.442+$ & .233 \\
\hline $1992-94$ & $-.574 * *$ & .200 & $-.551 * *$ & .200 & $-.548 * *$ & .200 \\
\hline 1995-98 & $-.885 * * *$ & .196 & $-.873 * * *$ & .196 & $-.862 * * *$ & .196 \\
\hline 1999-2000 & $-1.186 * * *$ & .307 & $-1.178 * * *$ & .307 & $-1.160 * * *$ & .304 \\
\hline Constant & $-6.943 * * *$ & .538 & $-6.961 * * *$ & .596 & $-6.988 * * *$ & .595 \\
\hline Log likelihood(df) & \multicolumn{2}{|c|}{$-1355.02(17)$} & \multicolumn{2}{|c|}{$-1352.04(22)$} & \multicolumn{2}{|c|}{$-1352.34(19)$} \\
\hline$\# \mathrm{p}<.10$ & $* \mathrm{p}<.05$ & & .01 & & $<.001$ & \\
\hline
\end{tabular}

\section{Partner status (no partner)}

$\begin{array}{rcc}\text { Married } & 1.401 * * * & .315 \\ \text { Cohabiting } & .972+ & .502 \\ & .175 * * & .069 \\ & -.010 * * * & .003\end{array}$

Age(-16)

Age(-16) ${ }^{2}$

Education (general secondary or vocational) 
Table 6. Sensitivity Analysis, Effect of Prior Maternity Leave on Second Conception

Model

Baseline (Table 5, Model 3)

Alternative specifications of effect:

Specify effect as any prior leave exceeding 3 months

Specify effect as prior leave 19 to 36 months

Alternative sample restrictions:

Include person-months where respondent is at home or in school

Omit person-months when respondent is self-employed

Omit person-months when respondent is currently on maternity leave

Omit person-months when respondent unemployed or on maternity leavı

Omit person-months when self-employed, unemployed, or on mat. leave

Omit first five months following birth

Controls for unobserved heterogeneity:

Propensity score (estimated probability of taking extended mat. leave)

Structural covariates from extended maternity leave model 3 (Table 2)

Person-level random effects (shared frailty)

$.404 \quad .185 \quad .029$


TABLE A1. Descriptive Statistics, Covariates Used in Analyses, Analysis Sample, January of Selected Years

Mean Age

Education

Specialized secondary
General secondary/vocational
Less than secondary
Married
Cohabiting
One child under three
One child three or older
Two or more three plus
Pregnant
Unemployed
On maternity leave
Employed for hire
Self-employed
Private sector employer
Branch of employment

Branch of employment

Health, social services

Public administration, safety

Finance, insurance

Occupation characteristics

Percent female (mean)
sd
Mean wage (logged)
sd

Ln(city size)

Moscow resident

\section{Regional variables}

Unemployment rate, centered Mean wage (logged), centered Percent ethnic Russian

$\begin{array}{rrrr}1988 & 1992 & 1995 & 1999 \\ 31.2 & 32.2 & 32.4 & 32.6\end{array}$

$\begin{array}{rrrr}24.7 \% & 24.7 \% & 25.7 \% & 27.2 \% \\ 33.2 \% & 33.8 \% & 34.5 \% & 34.6 \% \\ 36.5 \% & 36.5 \% & 35.7 \% & 35.0 \% \\ 5.7 \% & 5.1 \% & 4.1 \% & 3.2 \% \\ 71.0 \% & 69.7 \% & 64.9 \% & 58.5 \% \\ 3.0 \% & 3.0 \% & 3.8 \% & 5.6 \% \\ 21.4 \% & 17.7 \% & 12.9 \% & 10.8 \% \\ 59.9 \% & 67.4 \% & 68.5 \% & 68.3 \% \\ 25.3 \% & 30.9 \% & 31.1 \% & 29.4 \% \\ 4.4 \% & 2.7 \% & 2.5 \% & 1.6 \% \\ 1.0 \% & 2.2 \% & 4.5 \% & 7.9 \% \\ 10.8 \% & 9.7 \% & 7.9 \% & 5.3 \% \\ 88.0 \% & 87.4 \% & 85.9 \% & 84.0 \% \\ 0.2 \% & 0.7 \% & 1.7 \% & 2.8 \% \\ 5.1 \% & 12.1 \% & 18.8 \% & 27.3 \% \\ & & & \\ 8.4 \% & 10.0 \% & 10.8 \% & 12.7 \% \\ 3.6 \% & 3.5 \% & 4.5 \% & 5.3 \% \\ 1.0 \% & 1.2 \% & 1.9 \% & 2.5 \%\end{array}$

$\begin{array}{rrrr}0.73 & 0.75 & 0.77 & 0.78 \\ 0.25 & 0.24 & 0.24 & 0.23 \\ 6.34 & 6.31 & 6.31 & 6.31 \\ 0.32 & 0.33 & 0.33 & 0.35 \\ 3.42 & 3.32 & 3.24 & 3.26 \\ 19.4 \% & 17.8 \% & 16.9 \% & 16.9 \% \\ & & & \\ 0.00 & 0.06 & -1.18 & -2.29 \\ -0.07 & -0.05 & 0.02 & 0.04 \\ 82.9 \% & 83.2 \% & 82.6 \% & 83.1 \%\end{array}$

Note: Entries pertain to 15-44 year old women currently in the labor force, living in Russia. 